\title{
2015 Dr Lindsay E Nicolle Award
}

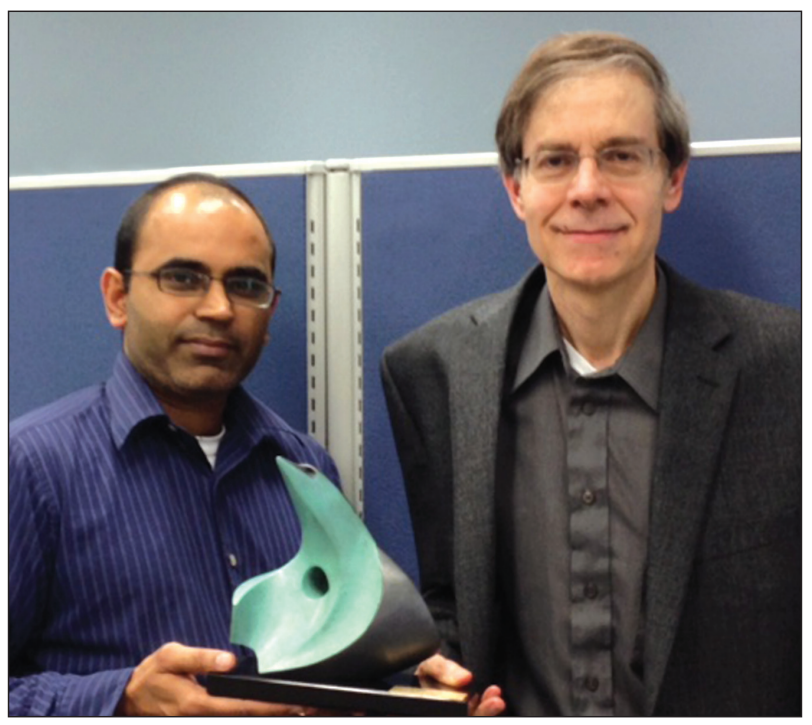

Dr Lalit Saini (left) and Dr Joseph M Brandwein are pictured with the 2015 Lindsay E Nicolle Award. Dr Saini accepted the award for the article 'Serum voriconazole level variability in patients with hematological malignancies receiving voriconazole therapy' (L Saini, JT Seki, D Kumar, EG Atenafu, DEC Cole, BYL Wong, A Božović, JM Brandwein. Can J Infect Dis Med Microbiol 2014;25[5]:271-276).

This annual award is sponsored by Pulsus Group and presented in honour of Dr Lindsay E Nicolle, the founding Editor-in-Chief of The Canadian Journal of Infectious Diseases $\mathcal{E}$ Medical Microbiology. The award is given to the author of the study that is deemed to have made a significant contribution to Infectious Diseases and Medical Microbiology, as demonstrated by the impact of the original research published in the Journal. The award consists of $\$ 1,000$ and a piece of Canadian art.

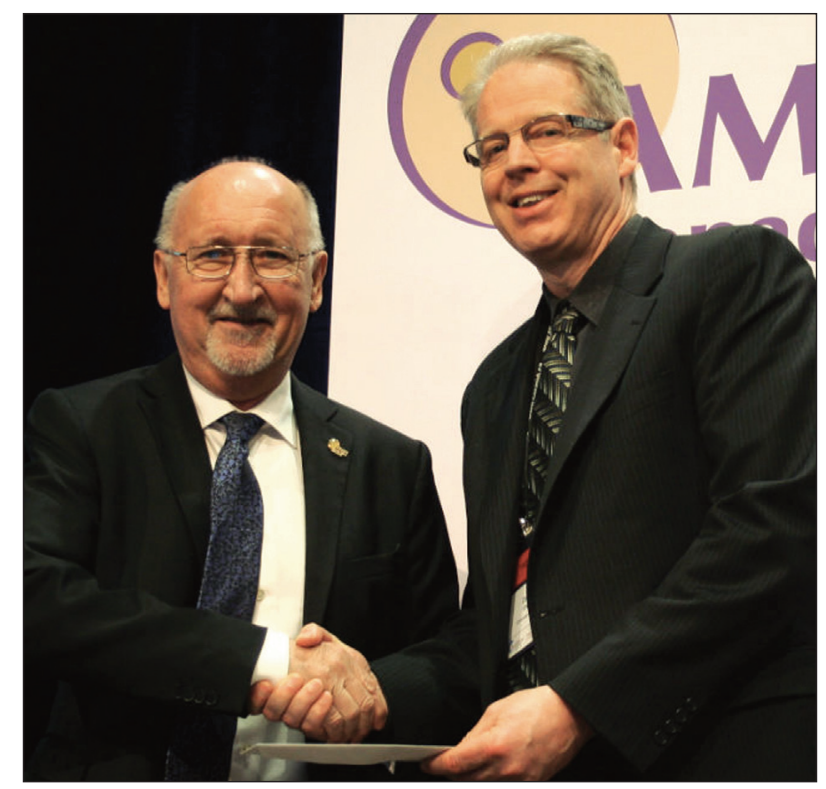

Robert B Kalina (left), Publisher of the Canadian Journal of Infectious Diseases $\mathcal{B}$ Medical Microbiology (CJID\&MM), presents a cheque to Dr Dan Gregson (right), President of the Association of Medical Microbiology and Infectious Disease Canada (AMMI). Each year, Pulsus Group gives a percentage of revenues associated with the Journal to the Society. As official Journal of this Society, the CJID\&MM serves as the key provider for publishing guidelines and resource information critical to their members and Canadian physicians. 


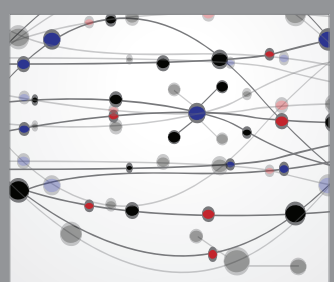

The Scientific World Journal
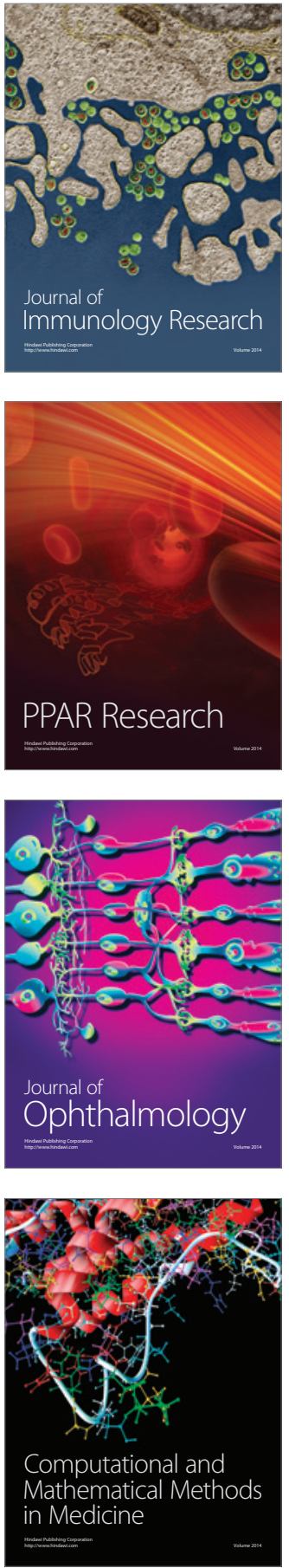

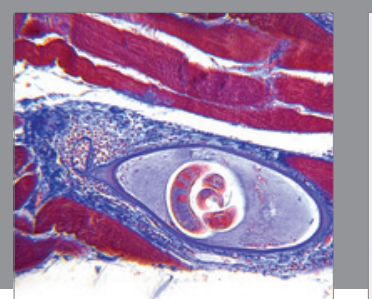

Gastroenterology Research and Practice

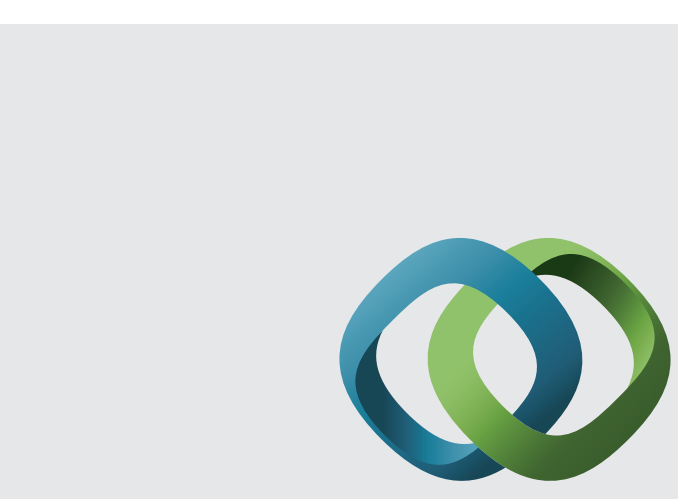

\section{Hindawi}

Submit your manuscripts at

http://www.hindawi.com
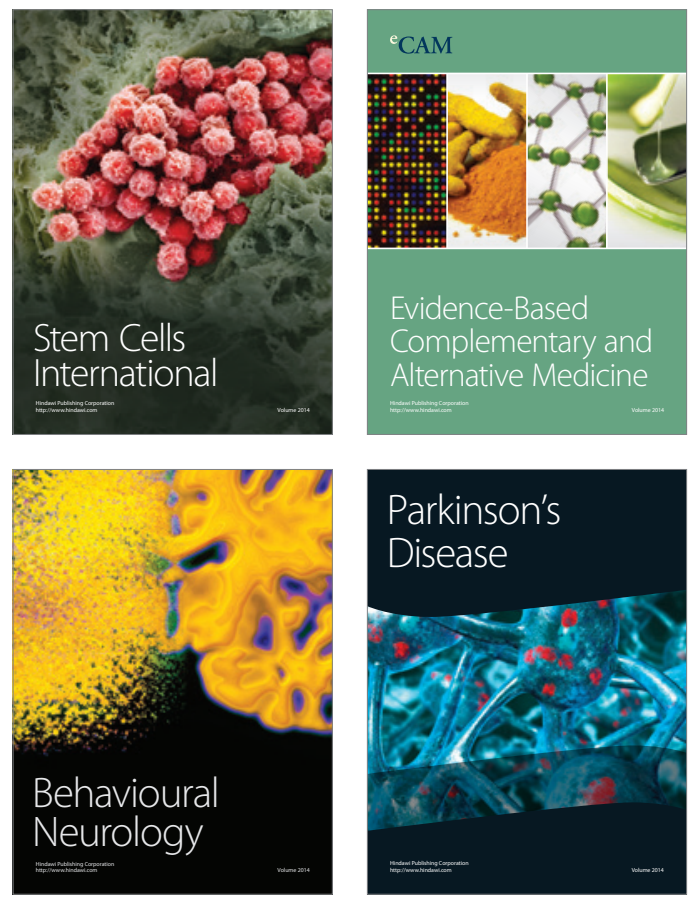
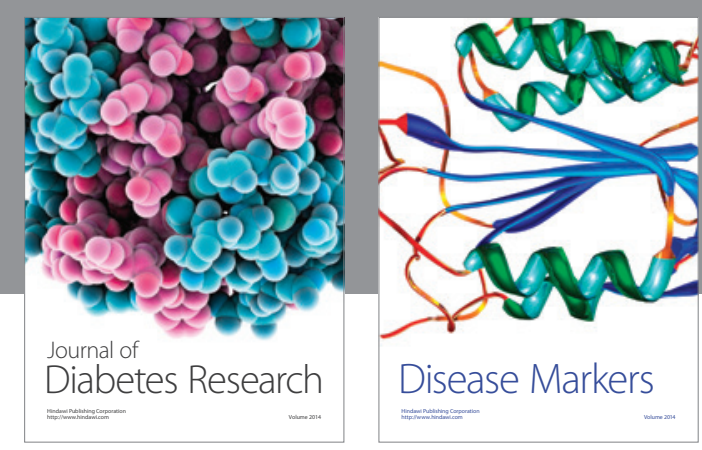

Disease Markers
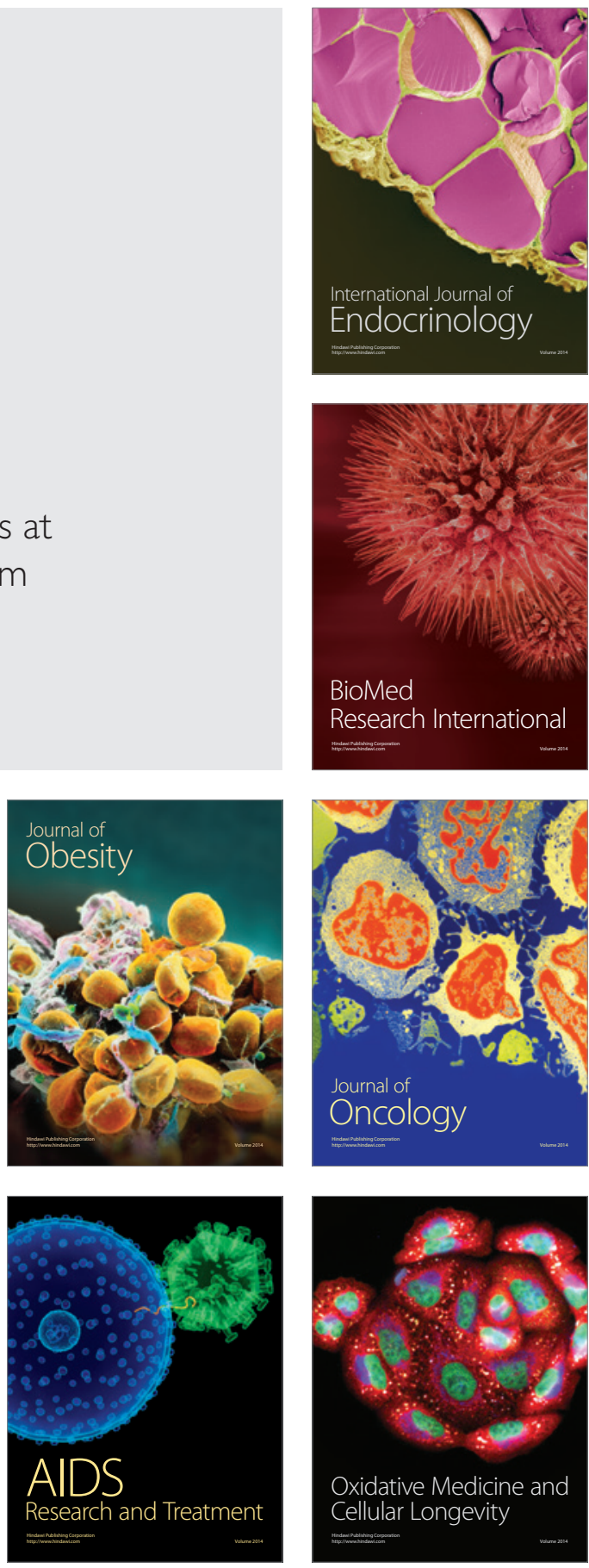